\title{
Sen's Conception of Freedom, and a Conjecture on Embodiment
} Fadi Amer

Abstract: This article explores Amartya Sen's understanding of freedom, and performs two central functions, one classificatory and the other substantive in nature. First, I situate his reflections within canonical understandings of liberty, finding an irreducible pluralism incorporating positive liberty in 'capability' alongside negative and republican liberty in 'process', which is subsequently unified in the notion of 'comprehensive outcomes'. Secondly, I attempt to find a normative referent for the intrinsic value of choice, and thereby indirectly that of freedom, in his account. In contrast to the liberal subjectivity one might - I believe, mistakenly - attribute to Sen's deployment of neoclassical economic frameworks, I instead argue for a re-interpretation of his account, inspired by the sociological literature on embodiment. Here, an 'encumbered' subject must inherit and transcend a normative totality to become an agent in the fullest sense.

Keywords: agency, choice, embodiment, freedom, liberty, subjectivity

In this article, I am principally concerned with Amartya Sen's account of liberty as it appears throughout his prolific career, performing two central functions. I aim to show that Sen's understanding of freedom is irreducible to any one of the views upon which the academy has settled for its baseline - the positive view of substantive opportunity, the negative view of non-interference and the republican view of non-dependence - for it is chiefly and unambiguously a pluralistic account. In its eclectic nature, however, this 
diversity tamed by the freedom to choose presents a radical knot embedded in its very understanding of subjectivity - a scepticism threatened with the looming danger of self-erasure. Accordingly, I shall also defend the notion of an embodied subject, whose corporeality provides the foundation for the intrinsic value of choice and freedom; and by which they may realise the fullest extents of their agency, thus undoing the metaphysical knot.

Beyond its scholarly interest in the powerful pluralism of Sen's account, this work aims at elucidating the theoretical substrate underlying the extraordinary calls for reform in this historic moment of discontent. Beyond the profound impacts of the COVID-19 pandemic - and the parochial understanding of freedom defended by anti-mask demonstrators - this past year has seen global protest movements denouncing nation-states as well as the grander political-economic order. Against visible injustice - for instance, the murder of George Floyd and the explosion of Beirut's port - one finds competing visions of a better, fairer tomorrow. This work therefore proceeds with the supposition that achieving meaningful progress demands that we question what is meant by the call for liberty. Accordingly, this work is concerned less with the specification of a telos than with the provision of a waypoint - a guide for broader and more inclusive discourse - as we forge on ahead in these trying times.

With the cautious optimism of a held breath, the rest of the article proceeds as follows: In Section I, I trace a broad outline of the canonical literature on liberty, consisting of the positive, negative and republican views as well as a fourth triadic view. In Section II, I unravel Sen's account of freedom, reflecting in its plurality each of these views in the notions of 'capability' and 'process', unified in the 'comprehensive outcome' model of individual advantage. Section III then offers a preliminary and exploratory investigation into the axiomatic claim that there is an intrinsic value to choice and freedom, finding inspiration in the sociological literature on embodiment such as to find its normative referent, while adding heft and substance to the becoming of the subject as an agent in the fullest sense. A concluding section finally synthesises this account of Sen's conception of freedom, and the conjecture on embodiment. 


\section{Section I: The Faces of Freedom}

To begin, I will survey the extant literature on liberty, foreshadowing the analysis of capability and process to come. Note that I shall use the terms 'liberty' and 'freedom' interchangeably, on stylistic grounds, following Lawrence Hamilton (2019) - and indeed Sen, who does so in practice despite occasional remarks otherwise. This overview will present four characterisations of liberty: negative, republican, positive and triadic. Of these, Isaiah Berlin's delineation of positive and negative liberty is perhaps the most salient in academic discourses, generating a conceptual binary between an affirmative account of self-determination and freedom from interference. Meanwhile, the republican account advanced by Philip Pettit and Quentin Skinner tests the logical limit of the negative account by emphasising freedom from the possibility of arbitrary intervention. Finally, the triadic account of liberty questions this dichotomous conceptualisation of freedom, pointing us instead in the direction of a structurally plural framework that unites the positive, negative and republican insights.

In his seminal work Two Concepts of Liberty, Berlin defines 'negative liberty' as freedom from interference by others (2002). Except, not every inability constitutes an unfreedom, and the concern here lies with the intentional interjection of other actors onto a sphere of action previously at one's disposal. There is thus a linear relationship between the extent of one's liberty, in negative terms, and the geometrical area of this sphere protected from intervention. This presents no obligation to determine the extent of the area, so long as it is taken as exogenously given and to be intervened upon. Under this view, we should not be concerned with the opportunities available to do and be in the world, but what one is unable to do precisely on account of another's deliberate meddling. An incumbent subject is therefore negatively free insofar as they are protected from the coercive interference of an antagonistic entrant.

Given this rejection of any attempt to direct human life towards particular ends, some authors cite the notion of negative liberty in the protection of a private sphere of agency held sacredly apart from the meddling of a public apparatus - particularly in the invoking of a social contract to restrain hostile individual action 
(Hamilton, 2016). Indeed, this is precisely the configuration found in the Hobbesian insight that 'by liberty is understood, according to the proper signification of the word, the absence of external impediments', (Hobbes 2008: 79-80). Likewise, I find in John Locke's Second Treatise the emphasis on 'liberty ... [from the] arbitrary will of another man', (Locke 2003: 110). As I will show, Sen is certainly sensitive to such principles of non-interference alongside possible deontological concerns, and these will be incorporated in his understanding of 'process' freedom. As a pluralist, however, his account remains irreducible to the negative conception alone.

Other authors find that non-intervention does not go far enough for a full account of freedom, promoting instead a 'republican' account of non-dependence or domination. In Skinner's (1998) formulation, direct coercion is unnecessary, although sufficient, to undermine liberty so long as one remains in a relationship of domination. That is, to be beholden to another wielding the power of arbitrary intervention is to condition one's liberty on their whim and cheerful disposition. To be dominated in this way entails that one's rights and liberties can be forfeited at any moment. Pettit extends this characterisation one step further by representing the relationship of domination in the case of a master and a slave: it may be the case that the former abstains from forceful command, allowing the latter to live as they so please, but that in itself is a far cry from a liberty worthy of the name (1999).

On these grounds, the argument goes, we ought not parochially investigate whether an agent is presently constrained; rather, we should determine whether there is even the slightest possibility of spontaneous meddling in their possibilities and opportunities. In this way, the appropriate essential designator for freedom becomes non-domination, for which it is both necessary and sufficient. Now, Pettit suggests that Sen's account aligns with this republican view if the capability approach entails a claim of non-dependence, where the project of development becomes fundamentally engaged not only in the maximisation of possible functionings, but also the minimisation of domination (2001). This turns out to be an unwarranted exaggeration, however, of Sen's amiability to wishing for independence from others - to be discussed in his notion of 'control'. While 
leaving it up to the individual to decide, Sen is quite clear that the sheer interconnectedness of contemporary human society prohibits any meaningful sense of independence.

In stark contrast, the positive conception of freedom stresses the importance of self-governance in determining one's doings and beings. This affirmative understanding stresses wielding one's fate as 'a subject, not an object', an active agent intentionally crafting and pursuing a personal conception of the good rather than a passive recipient moulded or directed by external forces (Berlin, 2002: 178). In other words, where previously I described the limitation of an exogenously given sphere of agency by a set of constraints, this positive account is primarily concerned with maximising the volume of the existential solid and the ability of the subject to wilfully craft the life they lead, in terms of a set of opportunities, capabilities and possibilities. We are thus concerned, under the positive view, with the prospects available to the subject to pursue their personal conception of the good, of their own accord and by their own choosing.

Under these terms, a totalitarian plenty does not constitute liberty precisely on account of its coerced imposition of a mode of being - even if it happens to be maximally desirable. In this conjunction of opportunity and free choice I find Georg Hegel's insistence that the essential being of the spirit lies in self-determination, criticising negative freedom as an abstraction (2011). Similarly, Jean-Jacques Rousseau's social contract aims at free self-governance guaranteed by equal and indivisible participation in collective democratic union (2002). Decisively, in both accounts, the will is emphatically characterised as a rich driver of human becoming. Along these lines, I must agree with Hamilton that, if compelled to choose only one designation, Sen would most comfortably endorse a positive conception of liberty (2019). Yet Sen's emphasis on capability - in his understanding of 'substantive opportunity' - does not undermine the irreducible plurality of his framework, embracing freedom's multiple faces without imposing a prior hierarchy.

Throughout this survey, I have repeatedly pointed to the possibility of engaging multiple conceptions of freedom at once, as I will soon show unfolding in Sen's own account. To accommodate such a malleable scaffolding, I must now begin the work of introducing a 
pluralistic account of freedom, casting an interrogative light on the positive-negative binary, and the separation of liberty into distinct and rival accounts more broadly. Earlier, I hinted at Hamilton's insight that the positive-negative distinction is but a false dichotomy, masking the broader distinction between a protected private sphere apart from a shared public domain (2016). Oppenheim takes our doubt a step further, suggesting that it does not make any sense to discuss freedom as such, as one of the abstract moments hitherto mentioned, for freedom can only ever refer to a fundamentally intersubjective relation: 'being free to do something with respect to someone else' (1961: 211).

There is thus the union of 'the freedom from' and 'the freedom to' between an incumbent and an entrant, from which one can, only abstractly, separate the positive and negative moments. This view is further extended by Gerald MacCallum, arguing that it is not the case that there is one kind of freedom superior to all else, and indeed we would be mistaken to conceive of freedom as inherently fractured (1967). Rather, he insists that freedom is best thought of as a 'triadic relation ... [with the form] $x$ is (is not) free from $y$ to do (not do, become, not become) $z$ ', (ibid: 312). Under this view, freedom is here being defined as a trivariate function $f(x, y, z)$ in which an agent $x$ must act, taking as given a series of constraints set out in relation to another agent $y$, simultaneously delineating the opportunities for doing and being $z$.

Except, Sen does not subscribe to this sense of simultaneity, seeing freedom as a social relationship at all times and necessarily expressing its opportunity and process aspects. As I will proceed to show in the following section, although the positive account is delineated most fully in his framework, he is resolutely opposed to any prior weighting between each of its forms. For that, he is certainly, and above all else, a pluralist with respect to liberty. In this way, Sen takes after Berlin who, having introduced the positivenegative binary, goes on to suggest that 'the ideal of freedom [is] to choose ends without claiming eternal validity for them, and the pluralism of values connected with this', (2002: 217). Having probed the positive, negative, republican and triadic accounts, I thus end this planetary excursion with a cosmic glance: a fundamental pluralism circumscribed by the freedom to choose, now ready to be disclosed. 


\section{Section II: Sen's Conception of Freedom}

In this section, I aim to demonstrate the fundamental and irreducible plurality of Sen's account of freedom. Here, positive liberty is captured by his understanding of 'capability', as a proxy for 'substantive opportunity'. Meanwhile, negative and republican liberty are captured by his understanding of 'process', with reference to 'effective power' and 'control'. It is his notion of 'comprehensive outcomes', however, which unites elements of both opportunity and procedure into one holistic normative model of individual advantage, which I suggest contains two sets of opportunities temporally disjointed by an operation of process: where 'culmination outcomes' account for resultant states of affairs, 'reflective opportunities' incorporate prior moments of thoughtful deliberation, and a procedural movement moves the subject from the latter to the former. Throughout this analysis of its opportunity and process aspects of individual advantage, I will relate Sen's account to each of the positive, negative and republican accounts of freedom.

In assessing individual advantage, Sen relies on the notion of 'capability' as a proxy for 'substantive opportunity' without yet describing, however, how valuations are made. Here, he begins with the notion of functionings to refer to a person's actual doings and beings, realised achievements like being well-fed and participating in communal life (2000). On this basis, he proceeds to inductively define capabilities as 'the substantive freedom to achieve alternative functioning combinations' (2010: 75) - that is, the set of all possible functionings that a subject could possibly achieve, and from which they can choose to pursue a privileged set of particularly valued ends. In other words, capability can intuitively be described as 'the power to do something', the abstract ability to realise all attainable functionings from which the subject may then pursue their personal conception of the good, after accounting for numerous individual, social and environmental heterogeneities, among others (2010: 19).

These desirable outcomes are then concretely separable into the subject's 'agency' and 'wellbeing' objectives (ibid). The two are not mutually exclusive, yet they are certainly irreducible to one another: Wellbeing goals relate to all those goods that promote the subject's ability to live a full and healthy life, while agency goals 
take on an explicitly existential character in the pursuit of a personal conception of the good (1985). The difference is quite salient in the example of the willingness to die for one's nation, a rupture with life itself nonetheless constitutive of a sense of purpose. It might seem as though the wellbeing account reduces the subject to a voiceless 'patient', a coerced recipient of externally directed aid (2000). Yet Sen is absolutely clear that interventions may rarely override consent, given the central importance allotted to the freedom to choose as a central feature of a distinctly human life (2010).

Emphasising this 'fundamental relevance of the choice act', I can now elaborate on the 'reflective opportunities' available to the subject, and the manner in which they select privileged ends (1997: 745-746). Here, I distinguish between two interrelated but distinct components: the possibilities for reflection on one hand, and the process by which the agent moves from reflection to their desired outcomes on the other. I call these opportunities for reflection and reasoned deliberation 'reflective opportunities', encapsulating the notion that the freedom to choose requires the possibility of deciding what ends one is to pursue (Sen 2010). The substantive opportunity to privilege certain ends over others is inexorably linked with the prior opportunity to consider all available alternatives. The movement from reflection to action, meanwhile, always already presupposes this choice or its absence. The possibility to reflect, deliberate, weigh and evaluate, can thus be treated as a valuable opportunity in itself.

It is in Sen's notion of 'comprehensive outcomes', however, that elements of opportunity and procedure are coherently joined together in a holistic normative model of individual advantage. Here, the notion of 'culmination outcomes' as resultant states of affairs - the consequences of choices taken as exogenously given is insufficient in characterising the pluralistic account. Rather, one must look to what he calls 'comprehensive' outcomes, an evaluation of states of affairs incorporating not only consequences but also the procedures through which they arise $(2000,2010)$. Having already made the case for reflective opportunities, I can now suggest that in this model there are in fact two different sorts of opportunities set apart by a procedural movement. That is, the comprehensive outcome must incorporate not only the culmination outcome, but also the reflective opportunities available to the subject, along with the operation of process that moves them from the latter to the former. 
Defining comprehensive outcomes in this way is crucial in understanding Sen's account of freedom, as it renders explicit persons' abilities 'to choose to live different kinds of lives within their reach, rather than confining attention only to what may be described as the culmination - or aftermath - of choice', (2000, 2010: 237). His repeated example of choosing to ritually fast, versus being coerced into starvation, emphasises the importance of possessing these reflective opportunities, and philosophically taking seriously the events leading up to the consequential outcome of a series of acts. Incorporating this notion of reflective opportunities in Sen's framework thus allows us to conceive of free decision and choice as a valuable opportunity in itself (2000). I will go on to show later that this is partially constitutive of the intrinsic value of freedom, looking at 'active choice' as a meaningful component of the good life (1993a: 44).

Having laid the groundwork, it is now clearer to see how Sen's concern for substantive opportunity, through capability, precisely encapsulates the germ of positive liberty - particularly in opposition to rival theoretical accounts like Rawls' understanding of justice as fairness. The central notion here is that if primary goods are proxies for or means to valued ends, then why not aim directly at the end itself (Sen, 1988)? In addition to people's diverse conceptions of the good, moreover, we ought to also consider their ability to convert their resources into valued ends $(1990,2010)$. It is thus the individual's capability set that stands for the person's freedom to do and be in the world, concerned less with actual achievements than the possibility to achieve. Rather than assuming a pre-ordained subject to be intervened upon, we thus begin to see how Sen's account places at its core the labour of agential becoming.

With this in mind, I can now return to the accommodation of negative and republican liberty within Sen's framework. Beginning with the former's censure of obstruction, recall that the negative account of liberty is fundamentally concerned with prohibiting the intervention of external actors precisely when it constitutes a rupture in the affairs of the subject. After all, there is nothing in the intrinsic nature of an intervention inimical to the incumbent, for it may just as well represent a helping hand or warm companionship. In this light, I referred to minimising the erosion of the existential solid, while excluding those interventions which contribute to 
its volume. Now, one might attempt to attribute to the capability approach a concern with its limitation, except it would remain indirect and retroactive - inverting the affirmative concern with opportunities to brute reaction to opposition. For that, I must instead turn to Sen's understanding of process.

To arrive at this result, I begin by introducing the notion of 'effective power', denoting the ability of a person to materialise preferred states of affairs irrespective of any direct machination of the grand causal levers of action $(1982,2010: 270)$. At its core, this relates to the notion of 'counterfactual choice': what would have been chosen by the subject if they possessed full control over the situation (1983, 1985). The subject therefore retains 'decisional autonomy' as the author of their own possibilities without these being decided by an external actor (1993b). Yet there is no need for direct control here, invoking instead that whole matrix of interpersonal influence and collaboration so central to lived human life (2010). By the broad notion of 'control', and the 'effectiveness' of preferences, I thus mean this power to align thought with being and transform the material topography according to one's wishes (2010).

Nevertheless, the desired outcome may be dependent on a particularly scarce resource, limited in either availability or entitlement, placing the subject's attainments in precarity. Insofar as these concerns stem from reliance or susceptibility to other persons, the subject's independence would be necessary and sufficient for eliminating this interpersonal danger. Accordingly, the logical extreme of this sort of reasoning would be 'direct' control: a person's wilful actions unambiguously, and without mediation, bringing about desired outcomes, casting aside 'effectiveness' as failing to capture the essence of agential potency (2010). Crucially, sensitivity to control does not commit us to a binary, instead conceiving of a continuum with its apex representing the special case of direct control (1985). Through this lens, Sen's framework allows us to evaluate states of affairs given the availability of substantive opportunities as well as decision-making and execution processes, in which control would serve as a supplemental point of consideration.

It turns out that the notion of effective power constitutes a preliminary, albeit insufficient, step in accommodating the negative insight of 'immunity from interference', (1993b: 524). In this framing, the effectiveness of the subject's preferences is inversely proportional 
to another's obstruction of their affairs, and so minimising such intervention is sufficient for an increase in one's own power. But it remains hardly necessary, so long as one's power might indeed be predicated on the cooperation of another. The effective power view therefore fails to express the negative insight in full, at least partly because it, like capability, is an affirmative notion, definitionally related to the ability to realise substantive opportunities. In its preoccupation with action at a distance, it neglects the nature and texture of the gravitational bond: a consideration of process must more fully incorporate concerns of interference and dependence, looking beyond the ability to materialise particular culmination outcomes.

Except, perhaps there is no particular need to situate the negative insight with a singular expression. Indeed, the notion of process as the bridge uniting reflective opportunities and culmination outcomes should provide a sufficiently broad framework with which to theorise the importance of non-interference. At this juncture, Sen's scepticism of reductive consequentialism opens up just enough room to seriously incorporate procedural and deontological demands (2010). Indeed, in his work I find reference to the notion that individual freedom breeds some meaningful sense of social obligation to others (ibid). Relying purely on substantive opportunity, in its particularly affirmative character, would fail to sustain this duty-based sort of moral reasoning. Having excised this opportunity aspect from our account of comprehensive outcomes, it can only be process that plays this central function. As I will demonstrate, Sen's insistence on the plurality of his account, and the freedom to choose, will bolster this assertion.

Moving onwards, I will now proceed to show how the republican understanding of liberty is subsumed in Sen's understanding of control. Recall that the central point of contention here is that an account of liberty ceasing at non-interference fails to recognise and dismantle relations of domination. That is, although direct intervention is sufficient in undermining liberty, it is not necessary so long as there remains the possibility of arbitrary interference - even if what comes about is in alignment with what the subject wishes, or would have wished, as an otherwise desirable outcome might materialise through reprehensible means (1982). Accommodating the republican insight into Sen's framework, based on the analysis that has thus far been presented, therefore requires grappling with the 
following conceptual constraints: that the claim of non-interference fits amorphously within the container of process freedom; and that the notion of effective power is insufficiently sensitive to relations of domination.

Nonetheless, Sen's understanding of control exactly satisfies these demands. In the strictest sense of direct control, it is definitionally the case that the subject does not rely on or interact with another agent to achieve valued ends. Insofar as this arrangement represents an equilibrium, without an independent entrant wishing to extract from the incumbent their opportunities or resources - for example, through physical force - I see this as rendering arbitrary intervention structurally impossible. Indeed, the caricature of Robinson Crusoe readily comes to mind, wholly responsible for one's own doings and beings in the world. Yet Sen is right to argue that the interconnectedness of contemporary human society tends to prohibit such a radical form of independence (2010). To that end, one may resort to the stronger and broader case of the continuum of control, in which case the extent of one's republican liberty is taken as a proportion of one's self-sovereignty.

Having provided my own interpretation throughout this section, I am luckily not confined to speculation in defending Sen's plurality, for it develops organically throughout his career $(1988 ; 1998$; 2000; 2010). Indeed, over time, Sen comes to distinguish not only between the opportunity and process elements of freedom, but also the media of control and effective power. In these works, he considers freedom not only in terms of the maximisation of capability, but also as freedom from interference and the possibility of arbitrary interference. What's more, these latter moments are precisely construed as adding to our understanding of freedom as plural and diverse, rather than divisively taking away in its potential opposition to the affirmative account of capability. In this sense, he emphasises the diverse faces of liberty, taking seriously not only the positive expansion of substantive opportunity, but also the negative removal of interference, and the republican dismantling of domination.

In sum, each cog of the comprehensive outcome machine is intended to capture a unique feature of liberty. Where capability in the form of reflective opportunities and culmination outcomes adequately captures substantive opportunity, it is process which accounts for the negative and republican insights. Here, where 
effective power is able to accommodate counterfactual choice, it is unable to completely capture non-interference or even partially capture non-dependence. For this, I referred instead to the control view, in its strictly binary and broadly continuous forms, in order to fully incorporate procedural sensitivity within the framework. Though Sen's writings tend to emphasise capabilities, each facet has a role to play while maintaining room for disagreement on the relative importance of each such freedom (Hirai and Ikemoto, 2017; Sen, 2000). To that end, I now return to the role of choice as a valued functioning in its own right, and the ultimate arbiter of individual and social life.

\section{Section III: A Conjecture on Embodiment}

Having explicated Sen's pluralistic account, I now turn to his claim that freedom possesses an intrinsic value closely related to a free operation of will in the exercise of intentional choice (2000). Intuitively, this refers to the phenomenon whereby having a choice is valuable precisely because it can be rejected in an assertion of will. Despite its immediate appeal, the claim nonetheless presents the problem of how to reconcile the priority afforded to choice and freedom with a framework which prides itself in its agnosticism with respect to value. That is, if the relative weights of different ends ought not to be decided a priori but freely chosen by the subject, what shields choice and freedom from the very same interrogative spirit? At issue is not whether the exalted status follows logically, for indeed it does by analytic definition, but whether Sen is justified in the ennoblement to begin with.

In this final section, then, I defend the axiomatic privileging of choice and freedom in Sen's framework with an embodied view of subjectivity. What follows constitutes a preliminary investigation - indeed, a conjecture - into a question that it does not pretend to wholly solve. This defence is therefore not intended as a comprehensive treatment of the matter, but rather a foundation for further inquiry inspired by a particular body of work in the sociological literature. In my view, the language of embodiment uniquely underscores the material process of appropriating a notion of intrinsic value, as a lived rejection of nihilistic rumination. This subsequently 
demands sensitivity to concrete human experience, casting aside the abstract phantasm of analytical personhood and becoming ensnared in the quicksand of corporeality. To judge the suitability of embodiment as a normative referent for the intrinsic value of choice and freedom, I begin by introducing the notion of agency.

The concept of 'agency' has been discussed extensively in various bodies of work. Some take it to mean an individual phenomenon, like Margaret Archer (2014) in pointing to the reflexive operation of consciously choosing one from a multitude of possibilities. Others see agency as a relational phenomenon, like Ian Burkitt (2016) who emphasises that subjects act in the world and on one another in networked, interdependent relations. Still others are concerned more with the mind and its functionings, like the proponents of the 'belief-desire-action' framework (e.g. Smith 2004) and its critics (e.g. Hasselberger 2014). Given my primary concern with Sen's account, however, the naturalistic basis of action exceeds the scope of this analysis. By agency, I therefore mean nothing other than the phenomenon of exercising the pluralistic freedom to do and be in the world, a notion nevertheless incorporating elements of the individual and the relational accounts through the framework of embodiment.

To accentuate the differences of this conjecture, I begin by explicating the notably mathematical subjectivity one might - mistakenly, in my view - attribute to Sen's frequent deployment of neoclassical economic frameworks. In so doing, I will have set a baseline with which to compare my corporeal characterisation of an embodied subjectivity. To be effective, an interpretation of Sen's framework must capture its key features: capability as a barometer of substantive opportunity; a diversity of valuations and relative weights without prior normative prescriptions; choosing as a valuable functioning, insofar as value can be attributed to the choice act itself; and it must also make room for considerations of process. Given the nature of the rational choice framework, procedural elements will have to be retrofitted as outcomes to be valued and pursued. While shedding the moral force of deontological reasoning, this structurally imposed compromise nevertheless facilitates a deeper treatment of 'economic agency'.

This process begins by assuming that it is possible to assign a real number to every one of the subject's functionings - their real 
achievements - representing the extent of their expression. Insofar as one is able to quantify the whole series of a person's achievements, in this way, one can define functioning vectors: mathematical groupings of real numbers representing the actualisation of each dimension under consideration (Sen 2000). Given the inductive definition of capabilities on one's functionings, one then finds that the capability set - as the set of all attainable functionings - will be the set of all such vectors (or n-tuples) achievable by the subject (Sen 1988). That is, in n-dimensional space, with each such dimension signifying the continuum of one particular doing or being in the subject's life, functionings would be represented as a Euclidean point, while their capabilities would be the set of all such points which are in principle realisable (Sen 1993a).

Based on this foundation, the crux of the economic interpretation is that the subject chooses their most valued functioning bundle out of their capability set. Here, consider the consumer in neoclassical microeconomic theory, who proceeds to choose a maximally desirable consumption bundle: first, specifying an evaluative strategy, represented by the mathematical function to be maximised - typically a consequentialist form of utility; secondly, choosing the consumption bundle that satisfies this evaluative strategy subject to the financial constraint of their budget. In the conventional microeconomic case, the consumer will maximise a convex utility function subject to a linear budget constraint such that every other alternative basket of goods can only be as good as the one ultimately chosen. Likewise, in the capability approach, it becomes clear to see how the subject is to choose their most valued bundle of functionings subject to the existential constraint of the substantive opportunities available to them.

And yet, the capability approach takes the freedom to choose far more seriously than it is incorporated in consumer choice theory. In particular, if the freedom to choose were to serve a merely instrumental importance, then the value of the capability set would be reducible to that of the chosen bundle of functionings (Sen 1988). This is precisely the 'special case' in which the capability approach mirrors exactly the consequentialist utilitarianism of the consumer problem in neoclassical microeconomic theory (Sen 1993a). Except, Sen insists that choosing a functioning bundle in a dearth of alternatives is hardly equivalent to a time of plenty. To be sure, 
this was the intuition invoked in choosing to ritually fast as opposed to suffering the unavoidable calamity of starvation. The capability approach must therefore allow for a valuation irreducible to that of the chosen bundle, taking seriously the act of choice as an important functioning in itself.

In order to account for this insight, Sen then defines the notion of a 'refined' functioning that incorporates the choice act alongside the chosen functioning bundle - in turn, allowing for greater normative flexibility in evaluating a given capability set while leaving room for the special case of consequentialism (Sen 1988). To be precise, the refined function $x / S$ formally denotes that an element $x$ is chosen from a set $S$ such that one may capture changes not only in the chosen object or bundle but also the size and substance of the set chosen from (ibid). Within this framework, to choose a bundle $x$ from a subset $A$ can potentially be intrinsically deficient to choosing that same bundle from its superset $B$. That is, evaluating the act of going hungry $h$ must take seriously whether the choice set $C$ includes the possibility of nourishment or a lack of entitlement to begin with.

It turns out, however, that this 'economic' sort of agency is unable to tackle the key paradoxes in Sen's attributing an intrinsic value to freedom, at least partially constituted by the intrinsic value of choice $(1996,2006)$. Notably, he makes perfectly clear that we are not obliged to adhere to any particular 'metaphysics of value' - broadly, any prior normative framework - so long as we agree on functionings and capabilities as constituting the relevant space of reasoned evaluation (1993a: 49). Indeed, Sen insists that the capability approach is quite consistent with multiple, conflicting answers to these meta-questions and weights applied to the valued objects of our respective evaluative domains. Yet, he does not provide guidance as to where the rational panacea will end the sceptical attitude's auto-erosion. After all, why is it that doubt should cease at the level of metaethics, and not question the very faculties of the subject?

Similarly, Sen is keen to include subjective and positional parameters within the framework of choice while insisting on its objectivity. He argues that the inclusion of mental processes does not necessarily negate the objectivity of the exercise so long as one: either impartially describes the relevant phenomena as they happen 
to be and without normative judgment; or critically examines the phenomena through thoughtful reflection and extensive public debate (Sen 1992, 2006). Sen goes even further in proceeding to define a function fit for a 'consistent moral approach' that takes seriously the incorporation of subject-relative parameters: a function of the form $f(s, a, p)$ in which the state of affairs $s$ is evaluated by person $a$ in the position $p$ (1985: 183-184). Yet, in each case, there is a reference to lived experience without a full delineation of its role in the choice and pursuit of diverse conceptions of the good.

The tension emerges, I now argue, from conceiving of human agency as an indeterminate cavity, a logical spectre onto whom a set of arbitrary predicates can be seamlessly sown. For this reason, there remains a sustained difficulty in reconciling Sen's insistence on abstaining from universal value judgments and privileging the individual freedom to choose, all while vehemently denying a nihilistic or subjectivist framework. It will instead be corporeality that grounds our understanding of the subject's agency and wilful choice of what is to be valued and to what extent. In other words, it is human embodiment that provides a normative referent for the intrinsic value of choice, and consequently at least partly the intrinsic value of freedom. Before I can proceed to the full analysis, I must now distinguish between the technical point being made and its material consequences for the developmental project that Sen is ultimately engaged in.

It may seem futile to find a normative referent for an object deemed intrinsically valuable, yet Sen clearly holds a stake in the metaphysical debate. Indeed, the axiomatic status held by freedom and choice, in the normative hierarchy of his approach, derives from a scepticism of value prescriptions that leads him instead to the material processes of individual reflection and public discourse. My conjecture therefore seeks to elucidate this central corporeality of human experience. Luckily, this sort of reasoning leads us naturally to Sen's foremost concern with the project of development above all theorising for its own sake (Meeks 2018). Indeed, his interest fundamentally lies in the lives that people actually manage to lead - notably, their substantive advantages or lack thereof (2000, 2010). In this spirit, the notion of embodiment aims to add existential weight to freedom and choice, in the process of becoming an agent in the fullest sense. 
Now, in its broadest usage, the term 'embodiment' refers to the material experience of sentience: having a body constrained by space and time, with all its urges, desires and upsets. Yet it also refers to how the body is simultaneously constructed by and used to navigate the social world. I am here inspired by two interrelated but distinct bodies of thought - what I refer to as the relational and affective accounts of embodiment, respectively. In the relational account, one is predominantly confronted with how the body is at least partially constructed by intersubjective forces and used to express agency within the social world. Meanwhile, the affective account describes the subjective experience of the world and reconfigurations of the body to achieve valued ends. It is these two accounts that will allow me to demarcate the subject's inherited normative landscape, and by distinction the physical labour that generates alternate social realities.

Delving into the literature, in the relational understanding of embodiment I find at least three distinct social constructions of the body. Tiffany Joseph, for instance, describes how membership in the national community is defined in terms of proximity to a prototypical body (2019). Similarly, Chantelle Marlor argues that modern scientific knowledge-creation must perform anonymity to be perceived as legitimate and fit for political appropriation (2010). Barbara Sutton, moreover, depicts the centrality of physically manifesting discontent to transcend bare intellectual commitment to an ideal (2007). In each case, the subject does not first exist as an atomic entity onto whom social relations are transplanted. Rather, the subject is fundamentally constituted intersubjectively, with embeddedness in the social world structuring the very being of the subject (Foucault 2003). Rather than considering corporeality the predicate of an abstract subject, the relational account demonstrates how sociality must first materially construct the subject before their pursuit of valued ends.

Similarly, I find at least three differing configurations of subjective experience in the affective account of embodiment. First, Daniel Fridman details the production of an idealised self through imagining and inhabiting a constructed world until performance becomes truth (2010). Michal Pagis, secondly, describes how sustained meditative practice infuses bare notional familiarity with profound subjective experience, to realise true knowledge (2010). Finally, Brian Lande depicts the production of a law enforcement 
officer in terms of configuring oneself to 'use [one's] hands as instruments of control', (2019: 1). Here, the liberal subjectivity's abstract segregation of mind and body dissolves into a fundamental, inseparable union (Zerilli 2015). Appropriating a concept consequently becomes corporeal engagement with the world in terms of learned behaviours and actions. This model therefore highlights how social relations become imprinted in one's perception of reality through repeated performance; and, inversely, how the creation of a self demands a deliberate labour of transformation.

As it turns out, the relational account of embodiment finds some resonance in Sen's own understanding of the sociality of human agency. Particularly, in Development as Freedom, I find the claim that 'individual freedom is quintessentially a social product' (2000: $31)$ taking into consideration 'personal characteristics, social background, [and] economic circumstances' (293). The choice act is accordingly always conditional on the subject's inherited landscape - that volatile exchange of intersubjective forces always shaping the field of play $(1998,2000,2010)$. By this I mean the whole range of social, political, and economic institutions that govern not only the rules of the game (North 1990), but also the definition of the players as such, the allocation of players to their respective teams and the moves that they have at their disposal. As a rule, the opportunities and choices available to the subject depend on the relational context from which they emerge.

Similarly, I find echoes of the affective account of embodiment in Sen's later works on the irreducible plurality of human identity. Particularly, in Identity and Violence, he argues that one is inevitably thrust into a series of affiliations (e.g. of nationality, class, profession) and yet it is wholly possible - indeed, quite likely - for one to participate in all at the same time without ceasing to be the same agent. Rather than happening upon a fixed or true identity, flux is a structural necessity as one must constantly construct the sort of lives they wish to lead, as materialised in one's chosen bundles of practices, norms, beliefs and values. Yet amidst conflicting demands, choice partially determines the extent and kind of one's membership. In this way, the act of choice becomes configured in terms of endorsing certain states of affairs deemed desirable or worth pursuing, a mechanism for expressing and expanding one's agency. 
Further similarities are likewise evident in Sen's analysis of multiculturalism, also in Identity and Violence. Here he compares competing views to cultural diversity, one celebrating the intrinsic value of juxtaposed difference, as in a 'mosaic' framework, and the other prioritising the freedom to choose one's identity, seeing reasoned endorsement as a necessary component to a diversity worthy of the name (2007). In disavowing the former and upholding the latter, Sen draws parallels with that critique of liberal subjectivity which sees the subject's relationship to the world as necessarily one of knowledge (Zerilli 2015). Namely, that it would be a mistake to consider identity as unequivocally reflecting full information on the possible alternatives available to the subject from which they can select consensually, according to some principle of maximal personal desirability (as in a 'revealed preference' account) (Sen 1996, 2000). Rather, one must account for the partial relational determination of identity through pre-existing intersubjective forces, as though looking out from the interior of a snow globe (2007). That is, only upon acknowledging the inheritance of a normative totality, for better or for worse, might one even begin to consider meaningful change.

Yet it is not merely in these reverberations that I glimpse Sen's sensitivity to the embeddedness of choice in lived contexts, given his deep concern for the material stakes of doing and being throughout his prolific career. He often describes, for instance, the relativisation of mental states to conditions of destitution (1992, 1998, 2000, 2006, 2010). Additionally, he repeatedly insists on the need to account for personal differences in converting primary goods to valued ends $(1985,1998,2000,2010)$. Likewise, he has drawn constant attention to the central role of entitlement failure in famines (1985, 1987, 1998, 2000, 2003, 2010). Finally, one can also point to the repeated emphasis on his traumatic personal exposure to the brutal violence that ensues when plural identities are reduced to militant singular affiliations above all else - as he often describes the massacres that accompanied the separation of the Indian subcontinent (1998, 2000, 2003, 2007, 2010).

Affirmingly, Sen identifies the fundamental agential role of choice not in 'jumping out of nowhere into somewhere, but [leading] to a move from one place to another', (2007: 35-36). This characterisation underscores the process by which the inherited normative landscape slowly becomes opaque in the eyes of the subject, 
through exposure to alternative worlds, recognising that ways of being in the world which seemed necessary and immutable are quite contingent and mouldable after all. That is, in a two-step process, the subject must first come to terms with the pre-existing reality as juxtaposed to concrete alternatives; and, following this reflective insight, they may begin the labour of producing a valued self - not only experiencing diverse possibilities but incorporating them into lived reality through habitual repetition and endorsement. From this lens, the consequent nuance in Sen's framework is that the subject takes as exogenously given a historical context over which they lack control, which nevertheless forms their pre-reflective engagements - a preliminary delineation of capabilities and evaluations over states of affairs. Yet through material exposure to alternate social realities, they may recognise the contingency of this inherited normative landscape; and, through deliberatively reflecting on the desirability of each such affiliation - its norms, beliefs, values and practices - the subject may then consent to a 'basket' of normative goods and functionings, forged in intersubjective deliberation.

Taking a step back, the central importance of choice lies precisely in its role in developing the subject's agency, from one of mere osmotic absorption of an existing whole to wilful, informed consent of a personal conception of the good. Yet a necessary component of choice's ability to perform this crucial agential function is its accounting for the material stakes of human life. In an admittedly peculiar characterisation of the point, there is a comfort in contemplating subjectivity as an immaterial plasticity ... a spirit, unperturbed by the shackles of corporeality; fully aware of its position in and relation to the perpetual void that it inhabits; possessing at once a divine clarity of its desires and, at a moment's notice, fully capable of reversing trajectories to chase its whims without a care or cost to consider. In such a hollow structure, it seems an entirely arbitrary decision to attribute an intrinsic value to choice, or to freedom for that matter. Absent a prior hierarchy of values, with no tangible consequence to any such instantaneous, uninhibited action, the axiomatic privileging of the exercise seems logically arbitrary as a castle in the sky. With the same scepticism that Sen takes to binding analytical frameworks fixed to meta-ethical positions, intolerant of diversity, one could equally cast doubt on the intrinsic desirability of anything. 
Except, I have repeatedly shown that Sen cannot possibly care for such a futile existence. At issue is an encumbered subjectivity, providing the normative referent for the intrinsic value of choice and establishing paramount continuity with the tangible stakes of development. By this I mean the labour of recognising one's embeddedness in an inherited scaffold - taking a reflexive glance at oneself from the outside - and, acknowledging its contingency, crafting a mode of being consistent with one's own notion of the good. Here, the creation of an entirely new set of values is unnecessary, both because of the logical separability of novelty from desirability as well as recognising the value deriving from reasoned consent. Embodiment accordingly accounts for the intrinsic value of choice, and indirectly at least partially that of freedom, in the active movement from an inherited totality to willed endorsement, facilitating the emergence of an agent in the truest and fullest sense.

\section{Conclusion}

To sum up, throughout this article I have traced the form and substance of liberty from various historical and theoretical reflections on the matter, through to Amartya Sen's account of freedom, ending with a metaphysical investigation into the very stuff that constitutes its intrinsic value. In Section I, I probed the canonical segregation of liberty into its positive, negative and republican elements, while also considering the triadic view for its emphasis on plurality. With this foundation, I set out in Section II an explication of Sen's conception of liberty, identifying a fundamentally and irreducibly pluralistic account in which the notion of comprehensive outcomes unifies each of its diverse moments. Where its opportunity aspect, corroborated in the account of capability, corresponds most closely to affirmative liberty, its process aspect, highlighted partially in the notion of effective power as well as its control account, underscores the importance of non-interference and non-dependence.

Except, the eclectic nature of Sen's account presented something of a paradox when it came to grounding the intrinsic value of choice, and thereby at least partially that of freedom. To square this theoretical circle, I introduced the relational and affective accounts of embodiment, addressing the social construction of the body and 
the labour of creating oneself. This exploratory account of embodied subjectivity built a metaphysical scaffolding around the axiomatic privileging of choice and freedom, and illuminated the process by which the subject inherits and transcends an exogenously given normative totality. Through the endorsement and rejection of its elementary particles, the piecemeal selection of their own mode of being in the world, one accordingly witnesses the agential becoming of the subject. In this way, the dyad of liberty and choice sustains an irreducible diversity fundamentally expressed in the vigorous mortality of an embodied human subject, to be refined in a future work.

\section{Acknowledgments}

I wish to thank the Cambridge Trust as well as Victoria College at the University of Toronto for their financial support, without which this incredible opportunity would not have been possible. I am also deeply indebted to my supervisors, Professor Lawrence Hamilton and Professor Maha Abdelrahman, as well as the Centre of Development Studies as a whole. I owe this most transformative year to your sharpness of mind and generosity of spirit.

FADI AMER recently completed his MPhil at the University of Cambridge, graduating with distinction and winning the Centre of Development Studies' dissertation prize. As a scholar of Lebanese origin, he is broadly interested in the social and economic development of the Middle East \& North Africa region, from which emerges his interest in questions of liberty and justice. Presently, he is looking to pursue doctoral study into the possibilities for industrial development in his home country, hoping to identify pathways to sustainable recovery from its recent tragedies - with over half the population now recognised to be in poverty. E-mail: fa391@cantab.ac.uk

\section{References}

Archer, M. S. 2014. Structure, Agency, and the Internal Conversation. Cambridge: Cambridge University Press. 
Berlin, I. 2002. 'Two Concepts of Liberty', in Liberty: Incorporating Four Essays on Liberty. Oxford: Oxford University Press.

Burkitt, I. 2016. 'Relational Agency: Relational Sociology, Agency and Interaction', European Journal of Social Theory 19(3): 322-339. doi: $10.1177 / 1368431015591426$.

Foucault, M. 2003. Society Must be Defended: Lectures at the Collège de France, 1975-76. New York: Picador.

Fridman, D. 2010. 'From Rats to Riches: Game Playing and the Production of the Capitalist Self', Qualitative Sociology 33(4): 423-446. doi: 10.1007/ s11133-010-9171-z.

Hamilton, L. 2016. Freedom is Power: Liberty through Political Representation. Available at: https://doi.org/10.1017/CBO9781107477698.

Hamilton, L. 2019. Amartya Sen. Cambridge: Polity.

Hasselberger, W. 2014. 'Human Agency, Reasons, and Inter-Subjective Understanding', Philosophy 89(1): 135-160. doi: 10.1017/S0031819113000727.

Hegel, G. W. F. 2011. Elements of the Philosophy of Right. Cambridge: Cambridge University Press.

Hirai, T. and Y. Ikemoto. 2017. 'Sen's Economics in The Idea of Justice: Induction vs Deduction', Review of Political Economy 29(1): 93-110. doi: 10.1080/09538259.2016.1259873.

Hobbes, T. 2008. Leviathan, or, The Matter, Forme and power of a Commonwealth Ecclesiasticall and Civil. New York: Touchstone.

Joseph, T. D. 2019. 'Race, Phenotype, and Nationality in Brazil and the United States', in N. Boero and K. Mason (ed.), The Oxford Handbook of the Sociology of Body and Embodiment. Oxford: Oxford University Press. doi: 10.1093/oxfordhb/9780190842475.013.24.

Lande, B. 2019. "'Laying hands" and Learning to Touch and Grab in the Police Academy', in N. Boero and K. Mason (ed.), The Oxford Handbook of the Sociology of Body and Embodiment. Oxford: Oxford University Press. doi: 10.1093/oxfordhb/9780190842475.013.34.

Locke, J. 2003. Two Treatises of Government: And a Letter Concerning Toleration. New Haven, CN: Yale University Press.

MacCallum, G. C. 1967. 'Negative and Positive Freedom', The Philosophical Review 76(3): 312. doi: 10.2307/2183622.

Marlor, C. 2010. 'Bureaucracy, Democracy and Exclusion: Why Indigenous Knowledge Holders Have a Hard Time being Taken Seriously', Qualitative Sociology 33(4): 513-531. doi: 10.1007/s11133-010-9168-7.

Meeks, G. 2018. On Sen on the Capability of Capabilities: The Story of a Notfor-profit Enterprise. doi: 10.1017/9781108559881.003.

North, D. C. 1990. Institutions, Institutional Change, and Economic Performance. Cambridge: Cambridge University Press.

Oppenheim, F. E. 1961. Dimensions of Freedom: An Analysis. New York: St Martin's Press. doi: 10.1037/14355-000. 
Pagis, M. 2010. 'From Abstract Concepts to Experiential Knowledge: Embodying Enlightenment in a Meditation Center', Qualitative Sociology 33(4): 469-489. doi: 10.1007/s11133-010-9169-6.

Pettit, P. 1999. Republicanism: A Theory of Freedom and Government. Oxford: Oxford University Press.

Pettit, P. 2001. 'Capability and Freedom: A Defence of Sen', Economics and Philosophy 17(1): 1-20. doi: 10.1017/S0266267101000116.

Rousseau, J.-J. 2002. The Social Contract: And, The First and Second Discourses. New Haven, CN: Yale University Press.

Sen, A. 1982. 'Liberty as Control: An Appraisal', Midwest Studies in Philosophy 7(1): 207-221. doi: 10.1111/j.1475-4975.1982.tb00092.x.

Sen, A. 1983. 'Liberty and Social Choice', The Journal of Philosophy 80 (1): 5. doi: $10.2307 / 2026284$.

Sen, A. 1985. 'Well-being, Agency and Freedom: The Dewey Lectures 1984', The Journal of Philosophy 82 (4): 169. doi: 10.2307/2026184.

Sen, A. 1987. 'Food and Freedom'. Available at: https://cgspace.cgiar.org/ handle/10947/556.

Sen, A. 1988. 'Freedom of choice', European Economic Review 32 (2-3): 269294. doi: 10.1016/0014-2921(88.90173-0.

Sen, A. 1990. 'Justice: Means Versus Freedoms', Philosophy \& Public Affairs 19(2): 111-121.

Sen, A. 1992. Objectivity and Position. University of Kansas, Department of Philosophy. Available at: https://kuscholarworks.ku.edu/handle/1808/12406.

Sen, A. 1993a. 'Capability and Well-being', in M. Nussbaum and A. Sen (eds), The Quality of Life. Oxford: Oxford University Press. doi: 10.1093/0198287976.001.0001.

Sen, A. 1993b. 'Markets and Freedoms: Achievements and Limitations of the Market Mechanism in Promoting Individual Freedoms', Oxford Economic Papers 45 (4): 519-541.

Sen, A. 1996. 'Rationality, Joy and Freedom', Critical Review 10 (4): 481-494. doi: 10.1080/08913819608443434.

Sen, A. 1997. 'Maximization and the Act of Choice', Econometrica 65 (4): 745-779. doi: 10.2307/2171939.

Sen, A. 1998. 'Individual Freedom as Social Commitment', India International Centre Quarterly 25/26: 53-69.

Sen, A. 2000. Development as Freedom. New York, NY: Anchor Books.

Sen, A. (2003) 'Freedoms and needs', in Human rights. Routledge.

Sen, A. 2006. 'Reason, Freedom and Well-being', Utilitas 18 (1): 80-96. doi: $10.1017 /$ S0953820805001846.

Sen, A. 2007. Identity and Violence: The Illusion of Destiny. London: Penguin.

Sen, A. 2010. The Idea of Justice. London: Penguin.

Skinner, Q. 1998. Liberty before Liberalism. Cambridge: Cambridge University Press. 
Smith, M. 2004. 'The Structure of Orthonomy', Royal Institute of Philosophy Supplement 55: 165-193. doi: 10.1017/S1358246100008675.

Sutton, B. 2007. 'Poner el cuerpo: Women's Embodiment and Political Resistance in Argentina', Latin American Politics \& Society 49 (3): 129-162. doi: 10.1353/lap.2007.0034.

Zerilli, L. M. G. 2015. 'The Turn to Affect and the Problem of Judgment', New Literary History 4(2): 261-286. doi: 10.1353/nlh.2015.0019. 